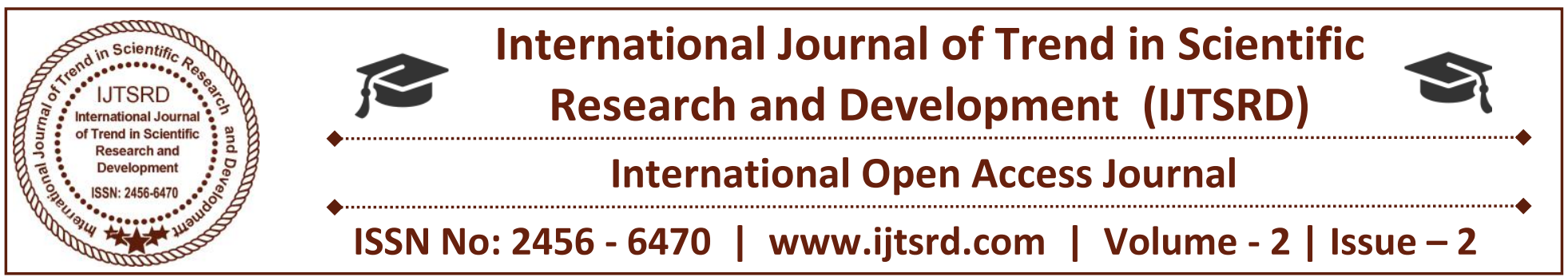

\title{
Mother's work profile in tribal communities and its effect on child feeding
}

\author{
Subhangi Sahoo \\ $\mathrm{PhD}$ scholar, Berhampur University, Berhampur, Odisha
}

\begin{abstract}
Background: Female labour participation is considered strong indicator of the growth of a country. Women in the rural set up constitute $26.7 \%$ of the workforce in $2015-2016$ (ILO, 2016). This study was taken up to understand the multiple roles and responsibilities taken up by the women from these tribal areas - starting with household to economic and child care responsibilities. The objectives of this paper is to explore the multiple work roles performed by tribal mothers of young children between (9-24 months) and the mother's combining work roles with child feeding.
\end{abstract}

Methods: It was a descriptive, cross-sectional study with data collection done at a single point of time. Study area comprised of 16 tribal villages in the Koraput district, Odisha. 200 households with children in the age group $(9-24$ months $)$ were selected by purposive sampling technique. Socio demographic details were collected. A time use study was employed to understand the caregiver's time allocation for different types of works at different times of the day.

Results: In the present setting, the women perform multifarious responsibilities both indoors and outdoors. The demand for women's time on household work, child care responsibilities and economic work is very high. Irrespective of the employment status of the mothers, child minding and care are entrusted to a caregiver, within or outside the family setting. The effect of the family type and caregivers involved in child care in the mother's absence are studied.
Conclusions: The hectic work profile of the mothers owing to the nature of the intensive nature of their work leaves them with limited time for child care responsibilities. However, the study reveals that the time spent by employed and unemployed mothers does not show much variation. Various strategies like carrying the child to the work site, engaging older siblings in child minding and feeding are used in the mother's absence.

Keywords: multiple work roles of mothers, caregivers, time use, feeding practices, tribal villages

\section{Introduction:}

The women's labour in poor households is critical to household economy. Women perform multifarious tasks which include household chores, paid or unpaid family labour along with child care (Bamji and Thimayamma, 1999). The tribal's are ethnic groups, dependent on subsistence economy.

The five major livelihood patterns followed by them include farm (crop, horticulture based and animal husbandry), forest (collection of edible and non edible forest products), wage (wage labour in agricultural fields or in government developmental work), migration (to nearby cities as labourers) and business (petty shops in the villages) / service based (driver, worker at mills etc). The shifting agriculture they practice in undulating terrains with lack of water facilities does not yield substantial benefits (Singh and Sadangi, 2012).

Numerous studies in India show that in addition to such typical domestic activities as cooking and 
cleaning, poor women spend considerable time collecting firewood, preparing cow dung cakes, or cleaning grain (Agarwal, 2001; Jain, 1985). These activities though not considered 'economic' either by the national accounts system or by the women themselves, are highly productive and called "marginal economic activity" or "expenditure-saving activity" (Desai and Jain, 1994; NSSO, 1980). Poverty of the physical environment, primitive implements, lack of capital pushes them further into the clutches of food insecurity and subsequent health conditions. The socio-economic milieu of the tribal's still remains unchanged.

The women play a critical role in agriculture depending on the coping strategies of the household changing cropping patterns and diversification. They take up wage labour activities in other's fields and care for the farm and household in case of migration of the male family members to nearby cities. The major agricultural operations are performed by the women. Be it primary or tertiary occupations, the women stand at the forefront of these activities. They are known to juggle household and economic activities along with child care with little leisure time. Binswanger-Mkhize (2012) echoes the same finding in their analysis of the structural transformation in India.

The children, in the age group $9-24$ months, covered under the study are completely dependent on the mothers and other caregivers for the satisfaction of their needs. Besides their basic needs like toilet training, bathing and dressing, the most pressing need is the feeding practices followed by the caregivers. Feeding is an intensive, time consuming activity and demands a chunk of the caregiver's time and attention. Hence the current study explores the time spent by mothers on various activities an $d$ how they manage child feeding practices.

\section{Methodology:}

The study was a descriptive, cross sectional study with data collection done at a single point of time. The samples (200 children in the $9-24$ months age group) were selected in consultation with the anganwadi ${ }^{1}$ worker present in the study village or the adjoining villages. The authenticity of the study child's age was verified from the anganwadi's register. Household visits were done to explain the purpose and get approval for their participation in the study. The caregivers were requested to sign a consent form.

The data collection on socio economic details and mother's time use was done by means of a structured survey. Observation of 100 households was conducted to validate the results of the feeding practices employed by the mothers, with the help of experts in the field.

\section{Results:}

\section{a. Socio demographic profile of the study households:}

According to the study results, most of the mothers $(33 \%)$ fell in the age group $25-30$ years followed by $32.5 \%$ mothers in the $20-25$ years category. The remaining majority $(22.5 \%)$ were in the age category $30-35$ years. While 8 mothers were very young $(15-$ 20 years of age) and mostly first time mothers. The other 4 mothers were older between 35 - 55 years. The categorisation of mothers based on the activity pattern reveals variability. Other than household work, all other activities are performed selectively by the mothers. Household and childcare activities are combined and performed by $93 \%$ of the mothers while $76 \%$ of the mothers carry out both household and economic work. A total $75 \%$ of the mothers collectively performed all jobs both within and outside the household along with their child care responsibilities. The categories of economic activities, performed by the mothers, is depicted in Figure 1.

The mothers from the 16 tribal villages belonged to different castes. Of the total 200 samples, the caste or tribe breakup are ST (77\%), OBC (11\%), the SC and Christians $(6 \%)$ each of the study population. The different castes include the Kandha (Santa) (39.5\%), Duruva (19.5\%), 8.5 percent are Bhumia's, 6 percent Paroja's and Bhatra's (4\%). The Harijan and Kangshari constitute $5.5 \%$ and 0.5 percent respectively in the SC category. The OBC population constituted the Gouda (6\%), the Kamara (4\%) and the Paika $(0.5 \%)$ respectively. The Christian comprise 6 percent only.

\footnotetext{
${ }^{1}$ An anganwadi centre provides basic health care and it is a rural mother and child care centre in India.
} 
Table 1: Socio demographic profile of selected mothers $(n=200)$

\begin{tabular}{|c|c|c|c|}
\hline Parameters & Category & No. & Percentage \\
\hline \multirow[t]{5}{*}{ Age } & $<20$ & 16 & 8 \\
\hline & $20-30$ & 131 & 65.5 \\
\hline & $30-40$ & 49 & 24.5 \\
\hline & $40-50$ & 2 & 1 \\
\hline & $>50$ & 2 & 1 \\
\hline \multirow[t]{10}{*}{ Caste } & \multirow[t]{5}{*}{$\mathrm{ST}(\mathrm{n}=50)$} & 24 & 37 \\
\hline & & 13 & 20 \\
\hline & & 6 & 9 \\
\hline & & 6 & 9 \\
\hline & & 1 & 2 \\
\hline & \multirow[t]{2}{*}{$\mathrm{SC}(\mathrm{n}=5)$} & 4 & 6 \\
\hline & & 1 & 2 \\
\hline & \multirow{2}{*}{ OBC $(n=7)$} & 4 & 6 \\
\hline & & 30 & 5 \\
\hline & Christian $(\mathrm{n}=3)$ & 39 & 5 \\
\hline \multirow[t]{7}{*}{ Occupation } & Agricultural work & 27 & 17 \\
\hline & Wage Labour ational J ourr & 13 & 9 \\
\hline & Collection of forest products & 13 & 9 \\
\hline & $\begin{array}{l}\text { Agriculture, wage labour and the } \\
\text { collection of forest products }\end{array}$ & 37.0 & 24 \\
\hline & $\begin{array}{l}\text { Wage labour and the collection of } \\
\text { forest products }\end{array}$ & 25 & 16 \\
\hline & $\begin{array}{l}\text { Agriculture and Collection of forest } \\
\text { products }\end{array}$ & 24 & 16 \\
\hline & Agriculture and wage labour & 13 & 9 \\
\hline \multirow[t]{2}{*}{ Family Type } & Joint & 104 & 52 \\
\hline & Nuclear & 96 & 48 \\
\hline \multirow[t]{3}{*}{ Family Size } & $4-6$ members & 123 & 61.5 \\
\hline & $>6$ members & 63 & 31.5 \\
\hline & $>4$ members & 14 & 7 \\
\hline \multirow[t]{2}{*}{ Land ownership } & Landed & 135 & 67.5 \\
\hline & Landless & 65 & 32.5 \\
\hline \multirow[t]{3}{*}{ Land Size } & $<2$ Acres & 83 & 41.5 \\
\hline & $2-5$ Acres & 32 & 16 \\
\hline & $>5$ Acres & 20 & 10 \\
\hline
\end{tabular}


Coming to the family type, majority $(52 \%)$ of the households belonged to the joint family type while $48 \%$ were nuclear families. The number of family members of the study households range from $\langle 4$ to $>$ 6. The minimum number of members present were 14 households while there were 63 large families with > 6 members. Land ownership of the households was an important deciding factor, in terms of the economic activities take up by the mothers. The present study covered $67.5 \%$ landed households and $32.5 \%$ landless households. However, these households $(41.5 \%)$ were essentially small farmers with $<2$ acres of land.

\section{b. Economic activities of the mothers / Caregivers:}

For analysis purpose, the number of children, have been grouped under different age categories. Majority $(34.5 \%)$ of thee mothers had children in the age group $10-15$ months followed by mothers (29.5\%) of children in the $15-20$ months category. The mothers with children in the $20-25$ months and 5-10 months were 20.5 and 15.5 percent respectively. A comparison of the economic activities performed by the mothers and the child's ages gave an insight of the nature of work taken up by mother's a few months after child birth. Nearly 14 mothers (35\%) wait till the child is $10-15$ months before resuming work. All activities, that require them to stay away from home for a long time, are temporarily abstained from. The mothers $28 \%$ and $22 \%$ respectively started taking up different kinds of economic works when the child attained $15-20$ months and became older than 20 months. Only $15 \%$ of the mothers with very young children (5 - 10 months) took up outdoor activities like agriculture, wage labour, collection of forest products etc.

Eight percent of the mothers with children between 15 - 20 months, took up wage labour and firewood collection together agriculture alone and agriculture along with collection of forest products was carried out by 5 and 6 mothers respectively. For mothers of older children $(20-25$ months $)$, the time spent on agriculture was more. Of these mothers, 5\% were engaged in agricultural work, $4 \%$ performed three fold activities (agriculture, wage labour and also ventured to the forests for firewood). Of the total 23 mothers in the age category ( $5-10$ months), only $6 \%$ and 5\% were performing time intensive activities outdoors. The activities either included a combination of agricultural work, wage labour and collection of forest products or agriculture along with collection of edible and non edible forest products. An indepth analysis was taken up to find the influence of family type and age of the child on the activities performed by the mothers. These figures are graphically represented in Figure No 1.

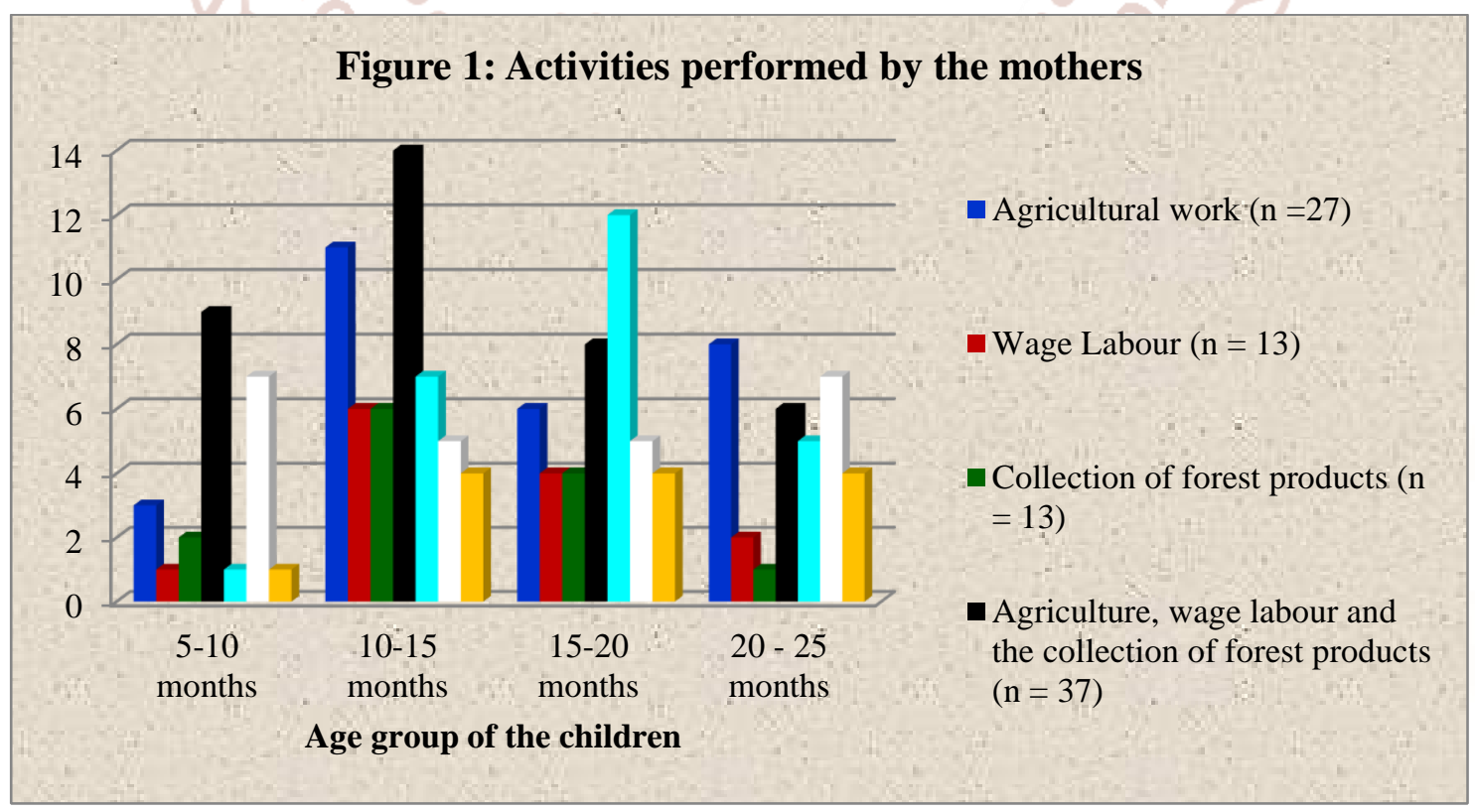

\section{c. Caregivers for child care support in the absence of the mother:}

Feeding of a child is conceived of as a 'female' activity which is usually done by mothers, older women or adolescent girls. This idea holds true even in the present study area. For following the caring practices, the caregivers need family resources and a 
support mechanism to help in childcare in her absence (Engle, 2002).

The difference between the caregivers engaged in child care based on the family type is negligible. The mother in law's presence at home is a major support system for the families be it joint or nuclear type. Ninety percent of the mother in law's were entrusted with child care responsibility. The caregivers of the child in the mother's absence included the brother and sister in law (12\%), the father and mother in law together $(10 \%)$ and the mother in law and older siblings (4\%). In one of these households, the great grandmother also took turn to care for the child in the mother's absence. In the nuclear families, 39\% of the older siblings performed child care responsibilities. Twenty nine percent of the father's were available at home to care for their children when the mother was away for work. In a few instances the brother and sister in law and neighbour's each (4\%) and both grandparents (7\%) took up child minding responsibility.

\section{d. Child feeding practices:}

Child feeding encompasses both breastfeeding and complementary feeding practices. The strong predictor variables of good influence on infant feeding practices include exclusive breastfeeding for at least 4 months, no prelacteal feeds for the child after birth and regular intake of staples. The other secondary factors which might have an influence the growth of the child include early initiation of breastfeeding, feeding on schedule, positive temperament of mother and child and supervised self feeding (Ramji, 2009).
All the 200 mothers breastfed their children. According to Rao and Rajpathak (1992), the lower the socio economic status, longer is the period of breastfeeding. The mother's in the study area have continued feeding their children as long as two years old. Of a total of 200 mothers, 194 (97\%) mothers initiated breastfeeding within 1 hour of birth. Only $3 \%$ of the mothers started it slightly late by 2 hours. At the time of the survey, 183 mothers were continuing breastfeeding along with complementary feed. As per the results of the survey, exclusive breastfeeding was continued till 6 months by 117 mothers $(58.5 \%)$ whereas another $71(35.5 \%)$ mothers practiced exclusive breastfeeding till the ideal age of 7 months. A major proportion of the mothers 126 (63\%) introduced complementary food for their child at the ideal age of 7 months. Of the 126 mothers, 118 mothers were continuing breastfeeding till the time of the survey. Only 8 mothers had stopped breastfeeding owing to deficit in milk supply and nature of work. 107 mothers of 126 also started giving water along with complementary food to their child at 7 months.

\section{e. Time spent by mothers on various activities:}

The activities performed by the mother's were either done singly or combined with other activities. The different activities included combinations like agriculture, wage labour and collection of forest products (24\%), only agricultural activities (18\%), wage labour and collection of forest products (16\%) and agriculture and collection of forest products $(15 \%)$. The remaining mothers performed only wage labour, collected forest products and engaged in both agriculture and wage labour ( $9 \%$ each).

\section{Figure 2: Economic Activities Performed by Mothers}

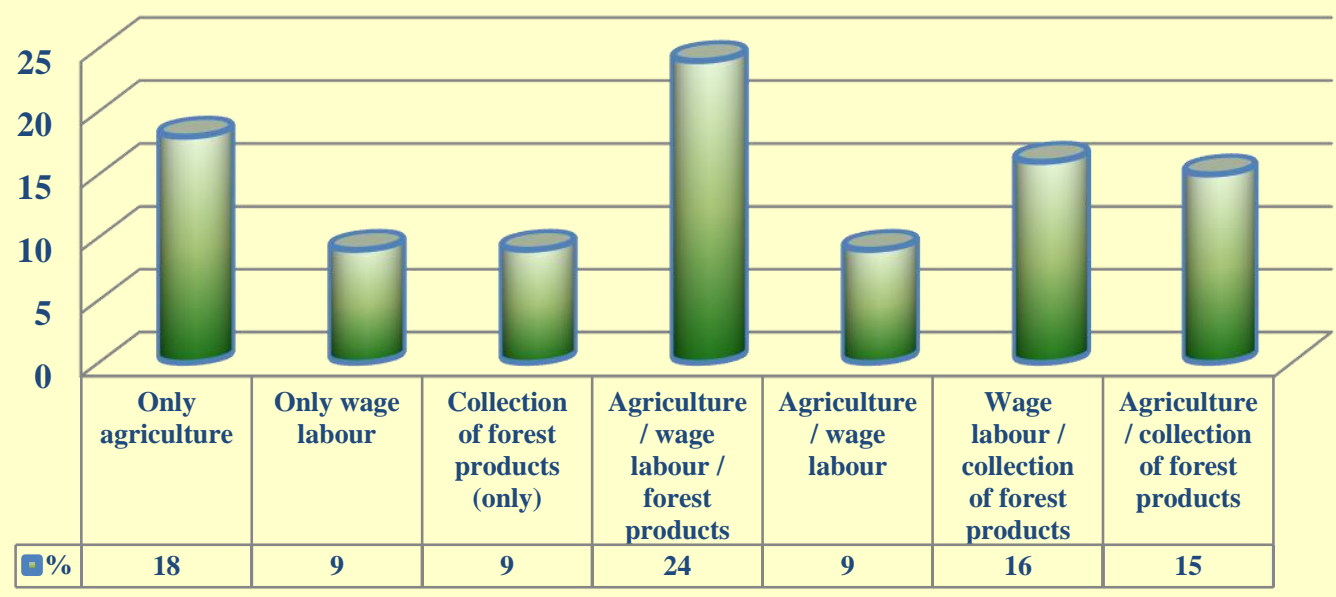


Table : The time spent by mothers according to their work status $(\mathbf{n}=\mathbf{2 0 0})$

\begin{tabular}{|c|c|c|c|c|}
\hline Occupational Category & Total Number & $\begin{array}{l}\text { Household Work } \\
\text { (min) }\end{array}$ & $\begin{array}{l}\text { Economic } \\
\text { Activity (min) }\end{array}$ & $\begin{array}{l}\text { Child care } \\
\text { (min) }\end{array}$ \\
\hline Unemployed Mothers & 48 & 246 & 0 & 168 \\
\hline \multicolumn{5}{|l|}{ Employed Mothers } \\
\hline Agricultural workers & 27 & 222 & 240 & 180 \\
\hline Wage labour activities & 13 & 228 & 228 & 180 \\
\hline $\begin{array}{l}\text { Collection of forest } \\
\text { products }\end{array}$ & 13 & 348 & 120 & 168 \\
\hline $\begin{array}{l}\text { Wage labour and collection } \\
\text { of forest products }\end{array}$ & 25 & 348 & 354 & 174 \\
\hline $\begin{array}{l}\text { Wage Labour and } \\
\text { agricultural activity }\end{array}$ & 13 & 70 & 456 & 180 \\
\hline $\begin{array}{l}\text { Agriculture \& collection of } \\
\text { FP }\end{array}$ & 24 & 348 & 360 & 156 \\
\hline $\begin{array}{l}\text { Agriculture, Wage labour } \\
\text { and collection of FP }\end{array}$ & 37 & 330 & 582 & 168 \\
\hline
\end{tabular}

Note: Unemployed mothers - mothers who perform only household works and are confined to their homes only. They might go outside but return back within half an hour or so.

Employed mothers - Mothers who are engaged in economic activities like agriculture, wage labour, gathering of forest products for sale in the local markets etc. These are performed either singly or in combination.

The time spent on household activities ranges between 222 to 348 minutes per day for employed mothers. However, for the unemployed category, the mean time spent on household work is 246 minutes. The economic activities of the mothers show wide variability with the minimum and maximum time equivalent to $120-582$ minutes per day. Collection of forest products and wage labour activities take up as long as $348 \mathrm{~min}$ per day each. Agriculture alone or in combination with wage labour and collection of forest products is equally time intensive and employs a large number of mothers $16 \%$ and $24 \%$ respectively. Child care time among employed and unemployed mothers does not show much variation. While unemployed mothers spend 168 minutes (2.8 hours) per day in child care, the employed mother's time ranges from 156 - 180 (ie: $2.6-3$ hours). Employed mothers spent a greater percentage of their available time beyond working hours with their infant in comparison to non employed mothers. The economic and developmental theorists stress on the importance of quality of interaction between mother and children (Booth et al, 2002).

\section{f. Assessment of child feeding practices:}

The infant feeding practices includes exclusive breastfeeding, initiation of complementary food along with breastmilk and feeding the child with only family foods and no breastmilk at all. While exclusive breastfeeding was followed by 117 mothers only, 198 $(99 \%)$ of the mothers were feeding the child with breastmilk and other family foods. With regard to feeding only family foods and no breastmilk, only 2 mothers had adopted this owing to insufficient milk for the child's feed. With majority of the children feeding on family food, there is a real need to understand the caregivers who are involved in child feeding and what meals they feed the child. Caregiver feeding the child in the mother's absence: For fifty two percent mother's who go for work outside for 4 hours, 42 children are fed once at least by the caregiver and 5 children are fed twice. In case of 24 mothers who remain outdoors for 3 hours, 15 and 4 children are fed once and twice respectively. The remaining 9 children are fed 1 time only except for 1 child who is fed twice when the mother is away for 2 hours. With regard to unemployed mothers, only 15 mothers entrust their child's feeding to a caregiver. While 8 caregivers fed the child 2 times in the 
International Journal of Trend in Scientific Research and Development (IJTSRD) ISSN: 2456-6470

mother's absence, 7 fed the child only once. All the mothers at least for child feeding. other children are in the care of their respective

Table: Caregiver's involved in feeding the different meals to the child.

\begin{tabular}{|l|l|l|l|l|l|}
\hline Categories & Breakfast & Snacks & Lunch & Snacks & Dinner \\
\hline Mother & $107(53.5 \%)$ & $63(31.5 \%)$ & $3(1.5 \%)$ & $75(37.5) \%$ & $172(86 \%)$ \\
\hline Siblings & $3(1.5 \%)$ & $1(0.5 \%)$ & $4(2 \%)$ & $5(2.5 \%)$ & 0 \\
\hline Grandmother & $45(22.5 \%)$ & $14(9 \%)$ & $15(7.5 \%)$ & $28(14 \%)$ & $2(1 \%)$ \\
\hline Uncle and aunt & $1(0.5 \%)$ & $2(1 \%)$ & $1(0.5 \%)$ & 0 & 0 \\
\hline Father & $23(11.5 \%)$ & 0 & 0 & $2(1 \%)$ & 0 \\
\hline Both grandparents & 6 & 0 & 0 & 0 & 0 \\
\hline Self feeding & $15(7.5 \%)$ & $4(2 \%)$ & 0 & $12(6 \%)$ & 0 \\
\hline
\end{tabular}

Note: the information is culled from the 24 hour recall questionnaire

As per the table, the mother is the primary caregiver of the child and feeds the child majority of the times. However, the meals are limited to only breakfast $(53.5 \%)$, snacks and dinner $(86 \%)$ which are not to major meals for a child. In comparison, the grandmothers are seen feeding all the major meals to the child. while $22.5 \%$ of them fed breakfast, $14 \%$ were available during the evening snacks. Lunch which is one of the major meals, is fed by only 7.5 percent. The role of the paternal uncle and aunt is negligible and limited to only child minding for a short while. Self feeding of snacks item is seen in 6 and $7.5 \%$ of the children. Hence there is a need to quantify the food intake of the child to actually estimate as to who is feeding the child appropriately.

\section{Discussion:}

Effective infant and young child feeding practices are essential for the healthy development of children under two years of age. Sarkar et al (2015), stress on the importance of, improved nutrition and hygiene for overall development of children. Studies on the improvement on the child's health owing to complementary foods given at $4-6$ months are limited (Kramer and Kakuma, 2003). According to the authors, (Ong et al, 2006, Morgan et al, 2003), the possibility that infant feeding and the time of initiation of complementary foods based on the infants weight also exists.
The various activities performed by women include household work, household and child care work and household along with economic work. In addition to this, the tribal women are known to engage in collection of forest products and kitchen garden activities which might take up additional labour and time. Though their work is left unrecognised, their ability to multitask, be it the home or the farm or the management of their children is explicit. There is a need to probe further into the mother's economic roles. Firstly, what is the effect of mother's absence and care taken by other caregivers? Secondly, the positive aspect owing women's control over resources and whether these mothers in the tribal set up are mere labourers in the field with no control over their resources.

\section{References:}

1. Agarwal B. Women, Poverty and Agricultural Growth in India. Gender and Development: Theoretical, Empirical and Practical Approaches. Vol.130. No. 3. Pp - 58. 2001.

2. Bamji, M.S and Thimayamma, B.V.S. Impact of women's work on maternal and child nutrition. Ecology of Food and Nutrition. Vol.39. No.1. Pp 13-31. 2000.

3. Binswanger-Mkhize and Alwin d'Souza, 2011 (b), "India, 1980-2008, Structural Change at the State Level." Background paper to Centennial Group 2012.

4. Booth, C. L.; Clarke-Stewart, K. A.; Vandell, D. L.; McCartney, K., and Owen, M. T. Child-care 
usage and mother-infant "quality time". Journal of Marriage and Family. Vol. 64. Pp - 16- 26. 2002.

5. Desai, S and Jain, D (199). Maternal Employment and Changes in Family Dynamics: The Social Context of Women's Workin Rural South India. Population and Development Review, Vol. 20, No. 1. Pp. 115-136. 1994.

6. Engle, P.L. Infant feeding styles: Barrier and opportunities for good nutrition in India. Vol. 60. No. s5. Nutrition Reviews. Pp - s109 - 114. 2002.

7. International Labour Organization, Global Employment Trends 2013: Recovering From a Second Jobs Dip (2013). World Economic Forum, "India," Economies. Pp - 79. 2016.

8. Jain, Devaki. "The household trap: Report on a field survey of female activity patterns," in Jain and Banerjee, $\mathrm{Pp}$ - 215-249. 1985.

9. Kramer MS, Kakuma R. The optimal duration of exclusive breastfeeding. A systematic review. Advances in Experimental Medicine and Biology. Vol. 554. Pp - 63-77. 2003.

10. Morgan J.B, Lucas A, Fewtrell M.S. Does weaning influence growth and health up to 18 months? Arch Dis Child. Vol. 89. Pp -728-33. 2003.

11. National Sample Survey Organization (NSSO). 1980. Sarvekshana, Vol. 3. New Delhi.

12. Ong KK, Emmett PM, Nobles S, et al. Dietary energy intake at the age of 4 months predicts postnatal weight gain and childhood body mass index. Pediatrics. Vol. 117. Pp - e503-e508. 2006.

13. Ramji, S. Impact of infant $\&$ young child feeding $\&$ caring practices on nutritional status \& health. Indian Journal of Medical Research. Vol. 130. Pp $-624-626.2009$.

14. Rao, S and Rajpathak, V. Breastfeeding and weaning practices in relation to nutritional status of infants. Indian Pediatrics. Vol. 29. No. 12. Pp 1533 - 1539. 1992.

15. Sarkar I, Dasgupta A and Das S. An assessment of nutritional status and feeding practices among children (under 2years) in a slum of Kolkata. International Journal of Health Science Research. Vol. 5. No. 6. Pp - 37 - 46. 2015.

16. Singh, A and Sadangi, B.N. Livelihood Patterns and Resource Base of Tribals in Koraput and Rayagada District of Odisha. Indian Research
Journal of Extension Education Special Issue. Vol. 1. Pp - $307-311.2012$. 